Article

\title{
Effects of Some Food Components on Non-Alcoholic Fatty Liver Disease Severity: Results from a Cross-Sectional Study
}

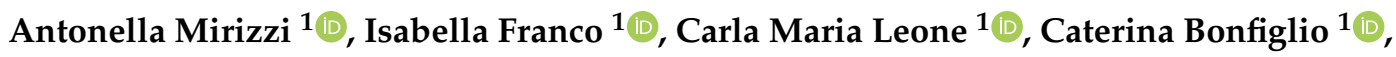 \\ Raffaele Cozzolongo ${ }^{2}$, Maria Notarnicola ${ }^{3}$, Vito Giannuzzi ${ }^{2}$, Valeria Tutino ${ }^{3}$, \\ Valentina De Nunzio $^{3}$, Irene Bruno ${ }^{1}$ D , Claudia Buongiorno ${ }^{1}\left(\mathbb{D}\right.$, Angelo Campanella ${ }^{1}$ (D), \\ Valentina Deflorio ${ }^{1}$, Annamaria Pascale ${ }^{1}$, Filippo Procino ${ }^{1}$, Paolo Sorino ${ }^{1} \mathbb{D}$ and \\ Alberto Rubén Osella 1,*(D) \\ 1 Laboratory of Epidemiology and Biostatistics, National Institute of Gastroenterology, "S. de Bellis" Research \\ Hospital, Castellana Grotte (Ba), Via Turi 27, 70013 Castellana Grotte, Italy; \\ antonella.mirizzi@irccsdebellis.it (A.M.); isabella.franco@irccsdebellis.it (I.F.); \\ carlaleone@interfree.it (C.M.L.); catia.bonfiglio@irccsdebellis.it (C.B.); irenebrunodiet@gmail.com (I.B.); \\ buongiorno.claudia@gmail.com (C.B.); angelocampanella7@gmail.com (A.C.); \\ valentinadeflorio@yahoo.it (V.D.); annamariapsc@hotmail.com (A.P.); filippo.procino@irccsdebellis.it (F.P.); \\ paolosorino96@libero.it (P.S.) \\ 2 Clinic Gastroenterologic Unit, National Institute of Gastroenterology, "S. de Bellis" Research Hospital, \\ Castellana Grotte (Ba), Via Turi 27, 70013 Castellana Grotte, Italy; raffaele.cozzolongo@irccsdebellis.it (R.C.); \\ vito.giannuzzi@irccsdebellis.it (V.G.) \\ 3 Laboratory of Nutritional Biochemistry, National Institute of Gastroenterology, "S. de Bellis" Research \\ Hospital, Castellana Grotte (Ba), Via Turi 27, 70013 Castellana Grotte, Italy; \\ maria.notarnicola@irccsdebellis.it (M.N.); valeria.tutino@irccsdebellis.it (V.T.); \\ valentinadx@hotmail.it (V.D.N.) \\ * Correspondence: arosella@irccsdebellis.it; Tel.: +39-08-0499-4655
}

Received: 29 October 2019; Accepted: 5 November 2019; Published: 12 November 2019

\begin{abstract}
Background: The high prevalence of non-alcoholic fatty liver disease (NAFLD) observed in Western countries is due to the concurrent epidemics of overweight/obesity and associated metabolic complications, both recognized risk factors. A Western dietary pattern has been associated with weight gain and obesity, and more recently with NAFLD. Methods: This is a baseline cross-sectional analysis of 136 subjects (79 males) enrolled consecutively in the NUTRIATT (NUTRItion and Ac-TiviTy) study. Study subjects had moderate or severe NAFLD diagnosed by using Fibroscan-CAP. Food Frequency Questionnaire was used to obtain information about food intake. Statistical analysis included descriptive statistics and a multivariable logistic regression model. Results: The mean age was $49.58( \pm 10.18)$ with a mean BMI of $33.41( \pm 4.74)$. A significant inverse relationship was revealed between winter ice-cream intake and NAFLD severity (O.R. 0.65, 95\% C.I. 0.95-0.99); chickpeas intake and NAFLD severity (O.R. 0.57, 95\% C.I. 0.34-0.97), and not industrial aged-cheeses type (O.R. 0.85, 95\% C.I. 0.74-0.98). A statistically significant positive association also emerged between rabbit meat (O.R. 1.23, 95\% C.I. 1.01-1.49), industrial type aged cheeses (O.R. 1.17, 95\% C.I. 1.01-1.35), milk-based desserts (no winter ice cream) (O.R. 1.11, 95\% C.I. 1.01-1.21), fats (O.R. 1.12, 95\% C.I. 1.01-1.25), and NAFLD severity. Conclusion: The fresh foods from non-intensive farming and high legume intake that characterize the Mediterranean diet would seem to be beneficial for patients with NAFLD.
\end{abstract}

Keywords: NAFLD severity; foods groups components; Food Frequency Questionnaire 


\section{Introduction}

Non-alcoholic fatty liver disease (NAFLD), characterized by excessive hepatic fat accumulation, is the most common liver disorder in Western countries and affects $17-46 \%$ of adults [1]. Studies conducted in the populations of Castellana Grotte and Putignano (Apulian Region, Italy) have confirmed that NAFLD is also highly prevalent (about 30\%) in this area, especially among elderly and male individuals [2,3]. Lifestyle interventions are the only known effective treatment for NAFLD [4,5], and changes in the dietary composition and consumption of individual food groups may have beneficial effects on NAFLD [6]. The way the food is produced, and how the animals are fed has been suggested to play a crucial role in health. Long-term bioaccumulation of antibiotic residues, for instance, may result in bacterial resistance [7,8], and gastrointestinal and liver problems [9]. The NUTRIATT (NUTRItion and Ac-TiviTy) Study is a nutritional randomized clinical trial (RCT), which enrolled subjects with moderate or severe NAFLD; it was a parallel-group randomized clinical trial aimed at estimating, as primary outcomes, the effect on NAFLD severity and the lipid red blood cells membrane profile of two different physical activity programs, of a Low Glycemic Index Mediterranean Diet (LGIMD) and their interaction as compared with a control diet. In this paper, we used baseline data to estimate associations between the consumption of some food group components with the grade of severity in NAFLD subjects enrolled in the NUTRIATT study before the intervention, while controlling for other food groups and demographics and biochemical characteristics.

\section{Materials and Methods}

\subsection{Study Design}

Details of the study design have been published elsewhere [10]. Briefly, NUTRIATT was designed as a randomized clinical trial (RCT) (https://www.clinicaltrials.gov, NCT02347696) which enrolled subjects with NAFLD in both hospital and general practitioners' settings.: Inclusion criteria were: (1) Body mass index (BMI) $\geq 25 \mathrm{~kg} / \mathrm{m}^{2}$; (2) age $>30$ years old $<60$; (3) NAFLD, moderate or severe. Exclusion criteria included: (1) Overt cardiovascular disease and revascularization procedures; (2) stroke; (3) clinical peripheral artery disease; (4) current treatment with insulin or oral hypoglycemic drugs; (5) fasting glucose $>126 \mathrm{mg} / \mathrm{dL}$, or casual glucose $>200 \mathrm{mg} / \mathrm{dL}$; (6) more than $20 \mathrm{~g} /$ day of alcohol intake; (7) medical conditions that may impair the participation in a nutritional intervention study; (8) people following a special diet, involved in a weight loss program, who had experienced recent weight loss, and inability to follow a diet for religious or other reasons. The study was conducted from March 2015 to December 2016. Subjects were encouraged to participate in the study by their general practitioners, and then they were followed during the study by Nutritionists regarding adherence to the Mediterranean Diet and by Motor Sciences graduates for the adherence to the physical activity program. Subjects received personal counseling from the initial phase of the study in order to complete all kinds of documentation. In this study, we present data from the NUTRIATT study obtained at baseline. All subjects gave their informed consent to participate, and the study was conducted according to the Declaration of Helsinki and approved by the Ethics Committee (Prot. n. 10/CE/De Bellis, 3 February 2015).

\subsection{Sample Size}

The trial sample size was estimated considering the repeated measurement nature of the outcome. From a previous study [11], the mean ( \pm SD) score of NAFLD was estimated to be 4.5 (SD 1) and 4.0 (SD 0.5), corresponding to $251-299 \mathrm{~dB}$ and $\geq 300 \mathrm{~dB}$ on the vibration-controlled elastography scale [12,13], for the treatment and control group, respectively; the type I probabilistic error was fixed at 0.05 (one-sided) and statistical power at 0.9 (type II probabilistic error 0.10 ). The correlation between baseline/follow-up measurements of the outcome was set at 0.4 . A sample size of $n 1=n 2=n 3=n 4=$ $n 5=n 6=20$ was estimated to obtain a lower categorization of NAFLD after three months. 
As this is a cross-sectional study we further investigated the minimum effect size detectable with different combinations of type I and II probabilistic errors for a sample size of 136 allocated in 2 groups. The maximum delta obtained was 0.4388 with a power of $95 \%$ and a type I probabilistic error of 0.001 . All differences among groups for different foods in our sample size were in this range.

\subsection{Data Collection}

At enrollment, patients were interviewed by trained nutritionists to collect data about medical history and lifestyle. Anthropometric (waist circumference (WC), hip circumference (HC), height, weight) and bio-impedentiometric analyses (Akern SRL, Via Lisbona 32/34, 50065 Pontassieve (FI) Italy) were also performed. A blood sample was drawn after $12 \mathrm{~h}$ fasting and frozen at $-80{ }^{\circ} \mathrm{C}$ until examination. All the analyses were performed within three months.

Pre-coded questionnaires were used to collect information on alcohol consumption, smoking, education (number of years) and the occurrence of myocardial infarction, stroke, diabetes. Trained interviewers collected information. The assessment of alcohol intake was performed using a questionnaire [14], and a personal interview.

Information regarding physical activity and the number of hours of sleep was collected using the International Physical Activity Questionnaire (IPAQ) [15].

Trained dieticians collected anthropometric data at the first visit. WC was taken using a measuring tape while the subject was standing opposite the nutritionist, wearing underwear, feet joined, abdominal muscles relaxed, arms hanging down the body. Weight was taken while the subject was standing, wearing underwear, on an electronic balance, SECA ${ }^{\circledR}$. Weight was approximated to the nearest $0.1 \mathrm{~kg}$. Height was measured with a wall-mounted stadiometer SECA ${ }^{\circledR}$, approximated to $1 \mathrm{~cm}$, while the subject was standing barefoot, with the heels joined at an angle of $60^{\circ}$, the head on the Frankfurt horizontal plane parallel to the floor, arms hanging down the body with the palms facing the legs, and the shoulders, and buttocks back against the wall; the measure was performed after a deep inspiration, at the highest point. Blood pressure (BP) measurement was performed following international guidelines [16]. The average of 3 BP measurements was calculated.

\subsection{Exposure Assessment}

Foods Groups

The European Prospective Investigation into Cancer and Nutrition (EPIC) Food Frequency Questionnaire (FFQ) was used to obtain information about food intake [17]. The input of the EPIC FFQ was made online on the dedicated site for the Italian EPIC study [17], and centralized elaboration was carried out by the National Cancer Institute, based in Milan.

FFQs items were fitted into 21 major food groups. Major foods groups were chosen not only to provide a comprehensive representation of the local diet but also taking into consideration the glycemic index and nutritional composition of foods. These groups were: Milk-Yogurt, Sweet-Milk Based Foods, Aged Cheeses, Fresh Cheeses, Meats-Eggs, Meat products, Non-starchy Vegetables, Fruits, Dried Fruits, Refined-Grains, Whole-Grains, Starchy Vegetables, Legumes, Added Sugar Sweets, Pastry-Biscuit-Bread, Fats, Alcoholic Beverages, Tea-Coffee, Fish, Non-Alcoholic Beverages, and Sauces or Dressings.

\subsection{Outcome Assessment}

The diagnosis of NAFLD was performed using vibration-controlled elastography implemented on a FibroScan ${ }^{\circledR}$ (Echosens, Paris, France). [18] NAFLD was categorized as absent $(<215 \mathrm{~dB})$, mild (215-250 dB), moderate (251-299 dB) and severe ( $\geq 300 \mathrm{~dB})[12,13]$. 


\subsection{Statistical Methods}

For descriptive purposes some variables were categorized: Age (30-40, 41-50, 51-60, 61 or $>$ ), Education ( $\leq 8$ years, $\geq 9$ years), Physical Activity (Low $\leq 4$ Metabolic Equivalent of Task (MET)-minutes-week, Moderate $=4-5.99$ MET-minutes-week, Vigorous $\geq 6$ MET-minutes/week), Smoking (Never, Former, Current). BMI was categorized following World Health Organization standards, whereas WC cut-offs were $<102 \mathrm{~cm}$ for men and $<88 \mathrm{~cm}$ for women [19].

All data are expressed as mean $( \pm \mathrm{SD})$ or percentages. Student's t-test was performed to estimate differences in the mean intake of Food Groups between Moderate and Severe NAFLD subjects.

Multivariable Logistic Regression (MLR) models were then performed to estimate the association between the exposure variables and the outcome. In this analysis Age was introduced as continuous variables. Results from MLR are expressed as odds ratio (OR) and 95\% confidence interval (95\% CI) adjusted for demographic and all other food groups. To disentangle the effects of some food groups components on NAFLD severity, the following strategy was used. First, an MLR with Foods Groups as independent variables was fitted; then, MLR with the component of each Food Group separately to aisle single food group components effect, and successively an MLR with disease promoting or preventing foods components identified in the precedent analysis. In the final analysis, estimates were adjusted by food groups (without the components identified as promoters or preventing), sex, age and kcal. As each food group component was present in only one group collinearity does not matter. A probabilistic type I error of 0.05 was considered as statistically significant. Statistical analysis was performed using statistical software Stata (Version 15.1), StataCorp, 4905 Lakeway Drive, College Station, Lakeway, TX, USA.

\section{Results}

In total, 166 subjects were assessed for eligibility. Seventeen did not meet the inclusion criteria; 6 declined to participate and 7 had incomplete FFQ $<90 \%$ answers. Thus, 136 participants ( $58 \%$ males) were finally included in this study. Bio-sociocultural characteristics, nutritional status, and other variables of interest are shown in Table 1. Mean age (SD) of participants was 49.58 (10.18) years, and mean energy intake was $2315.90(791.44) \mathrm{kcal}$. About $66 \%$ of subjects had higher education (university or tertiary education, completed or not). More subjects with overweight and different grades of obesity belonged to the Severe NAFLD category as well as higher waist circumference both in men and women. Severe NAFLD subjects had lower levels of physical activity and were current smokers. Seventy-eight percent of Moderate NAFLD subjects had F0/F1 grade of Stiffness. There was a good agreement between Fatty Liver Index and Fibroscan diagnosis.

Table 1. Bio-Sociocultural Characteristics, Nutritional status and other Variables of Participants. NutriAtt Study. Castellana Grotte (BA), Italy.

\begin{tabular}{|c|c|c|c|c|c|c|}
\hline & \multicolumn{6}{|c|}{ NAFLD $^{+}$} \\
\hline & \multicolumn{2}{|c|}{ Moderate } & \multicolumn{2}{|c|}{ Severe } & \multicolumn{2}{|c|}{ Total } \\
\hline & No. & $\%$ & No. & $\%$ & No. & $\%$ \\
\hline \multicolumn{7}{|l|}{ Age } \\
\hline $30-40$ & 9 & 34.6 & 17 & 65.4 & 26 & 100.0 \\
\hline $41-50$ & 20 & 41.7 & 28 & 58.3 & 48 & 100.0 \\
\hline $51-60$ & 13 & 35.1 & 24 & 64.9 & 37 & 100.0 \\
\hline $60+$ & 3 & 12.0 & 22 & 88.0 & 25 & 100.0 \\
\hline \multicolumn{7}{|l|}{ Sex } \\
\hline Men & 26 & 32.9 & 53 & 67.1 & 79 & 100.0 \\
\hline Women & 19 & 33.3 & 38 & 66.7 & 57 & 100.0 \\
\hline
\end{tabular}


Table 1. Cont.

\begin{tabular}{|c|c|c|c|c|c|c|}
\hline & \multicolumn{6}{|c|}{ NAFLD $^{\dagger}$} \\
\hline & \multicolumn{2}{|c|}{ Moderate } & \multicolumn{2}{|c|}{ Severe } & \multicolumn{2}{|c|}{ Total } \\
\hline & No. & $\%$ & No. & $\%$ & No. & $\%$ \\
\hline \multicolumn{7}{|l|}{ Education } \\
\hline$\leq 8$ years & 13 & 28.3 & 33 & 71.7 & 46 & 100.0 \\
\hline$\geq 9$ years & 32 & 35.6 & 58 & 64.4 & 90 & 100.0 \\
\hline \multicolumn{7}{|l|}{ Body Mass Index } \\
\hline $25-29.9$ & 13 & 41.9 & 18 & 58.1 & 31 & 100.0 \\
\hline $30-34.9$ & 27 & 42.2 & 37 & 57.8 & 64 & 100.0 \\
\hline $35-39.9$ & 3 & 12.0 & 22 & 88.0 & 25 & 100.0 \\
\hline$\geq 40$ & 2 & 12.5 & 14 & 87.5 & 16 & 100.0 \\
\hline \multicolumn{7}{|c|}{ Waist Circumference Women } \\
\hline$\leq 88 \mathrm{~cm}$ & 8 & 80.0 & 2 & 20.0 & 10 & 100.0 \\
\hline$>88 \mathrm{~cm}$ & 11 & 23.4 & 36 & 76.6 & 47 & 100.0 \\
\hline \multicolumn{7}{|c|}{ Waist Circumference Men } \\
\hline$\leq 102 \mathrm{~cm}$ & 16 & 47.1 & 18 & 52.9 & 34 & 100.0 \\
\hline$>102 \mathrm{~cm}$ & 10 & 22.2 & 35 & 77.8 & 45 & 100.0 \\
\hline \multicolumn{7}{|c|}{ Level of Physical Activity } \\
\hline Low & 2 & 22.2 & 7 & 77.8 & 9 & 100.0 \\
\hline Moderate & 13 & 40.6 & 19 & 59.4 & 32 & 100.0 \\
\hline High & 30 & 33.7 & 59 & 66.3 & 89 & 100.0 \\
\hline \multicolumn{7}{|l|}{ Smoking status } \\
\hline Never smoked & 29 & 36.3 & 51 & 63.7 & 80 & 100.0 \\
\hline Former smoker & 8 & 25.0 & 24 & 75.0 & 32 & 100.0 \\
\hline Current smoker & 8 & 33.3 & 16 & 66.7 & 24 & 100.0 \\
\hline \multicolumn{7}{|l|}{ Stiffness } \\
\hline F0 & 9 & 20.0 & 12 & 14.0 & 21 & 100.0 \\
\hline $\mathrm{F} 0 / \mathrm{F} 1$ & 26 & 58.0 & 47 & 55.0 & 73 & 100.0 \\
\hline $\mathrm{F} 1$ & 1 & 2.0 & 3 & 3.0 & 4 & 100.0 \\
\hline $\mathrm{F} 2$ & 6 & 13.0 & 9 & 10.0 & 15 & 100.0 \\
\hline F3 & 3 & 7.0 & 12 & 14.0 & 15 & 100.0 \\
\hline $\mathrm{F} 4$ & 0 & 0.0 & 3 & 3.0 & 3 & 100.0 \\
\hline \multicolumn{7}{|l|}{ Fatty Liver Index } \\
\hline$\leq 60 \%$ & 23 & 51.0 & 21 & 23.0 & 46 & 100.0 \\
\hline$>60 \%$ & 22 & 49.0 & 70 & 77.0 & 92 & 100.0 \\
\hline Total & 45 & 33.1 & 91 & 66.9 & 136 & 100.0 \\
\hline
\end{tabular}

${ }^{+}$NAFLD: Non-alcoholic fatty liver disease. Due to missing date some cells does not add up to 136.

Table 2 shows Biochemical Characteristics in subjects with NAFLD of Nutriatt Study. Homeostatic model assessment of Insulin Resistance (HOMA-IR), Glucose and Hemoglobin A1c IFCC (International Federation of Clinical Chemistry and Laboratory Medicine unit of measure) were substantially higher in Severe NAFLD subjects as well as glutamate-oxalacetate transaminase (GOT) and glutamate-pyruvate transaminase (GPT), C-Peptide and Insulin. 
Table 2. Biochemical Characteristics by NAFLD Severity. NutriAtt Study. Castellana Grotte (BA), Italy.

\begin{tabular}{|c|c|c|}
\hline & \multicolumn{2}{|c|}{ NAFLD $^{+}$} \\
\hline & Moderate & Severe \\
\hline & Mean (SD) & Mean (SD) \\
\hline $\mathrm{SBP}(\mathrm{mmHg}) \ddagger$ & $123.44(18.43)$ & $126.28(14.21)$ \\
\hline $\mathrm{DBP}(\mathrm{mmHg})$ & $80.78(9.35)$ & $81.83(7.28)$ \\
\hline HomA-IR $\S$ & $2.06(0.85)$ & $3.43(2.22)$ \\
\hline GLucose (mg/dl) & $92.20(7.16)$ & $101.51(21.56)$ \\
\hline Hemoglobin $\mathrm{A}_{1 \mathrm{C}}$ IFCC $(\mathrm{mmol} / \mathrm{mol})$ & $37.44(4.18)$ & $40.48(8.18)$ \\
\hline UREA $(\mathrm{mg} \%)$ & $35.67(9.54)$ & $34.30(9.23)$ \\
\hline CREatinine (mg/dL) & $0.78(0.18)$ & $0.79(0.18)$ \\
\hline $\mathrm{EGFR}(\mathrm{mL} / \mathrm{min} / 1.73 \mathrm{mq}) \mu$ & $108.59(100.59)$ & $85.98(20.44)$ \\
\hline Total Bilirubin (mg/dL) & $0.66(0.39)$ & $0.60(0.29)$ \\
\hline Direct Bilirubin (mg/dL) & $0.16(0.05)$ & $0.16(0.05)$ \\
\hline GOT (UI/L) i & $23.36(4.93)$ & $26.85(9.89)$ \\
\hline $\mathrm{GPT}(\mathrm{UI} / \mathrm{L})^{¥}$ & $28.60(10.17)$ & $35.73(20.29)$ \\
\hline GGT (UI/L)! & $22.56(10.84)$ & $28.88(22.73)$ \\
\hline IRON $(\mathrm{mcg} \%)$ & $86.69(32.01)$ & $99.42(100.34)$ \\
\hline Total Cholesterol (mg \%) & $203.76(35.66)$ & $198.32(40.47)$ \\
\hline HDL Cholesterol (mg/dL) & $49.67(13.18)$ & $42.38(10.11)$ \\
\hline TRIGLYCERIDES (mg \%) & $108.18(60.95)$ & $143.05(93.62)$ \\
\hline Ceruloplasmin (mg/dL) & $32.45(9.19)$ & $31.27(8.05)$ \\
\hline Alpha1 Antitrypsin (mg/dL) & $134.51(19.37)$ & $137.40(18.01)$ \\
\hline FT3 $(\mathrm{pg} / \mathrm{mL}) i$ & $3.46(0.47)$ & $3.38(0.37)$ \\
\hline FT4 $(\mathrm{ng} / \mathrm{mL})^{\$}$ & $0.85(0.10)$ & $0.87(0.13)$ \\
\hline Cortisol $(\mu \mathrm{g} / \mathrm{dL})$ & $11.87(4.74)$ & $10.01(4.17)$ \\
\hline C-PEPtide (ng/mL) & $2.53(0.70)$ & $3.38(1.31)$ \\
\hline INSULIN $(\mu \mathrm{UI} / \mathrm{mL})$ & $9.02(3.61)$ & $13.59(7.27)$ \\
\hline FERRITIN (ng/mL) & $140.71(146.19)$ & $139.41(152.69)$ \\
\hline Folate $(\mathrm{ng} / \mathrm{mL})$ & $6.24(2.84)$ & $6.01(2.73)$ \\
\hline VIT. B $12(\mathrm{pg} / \mathrm{mL})$ & $308.73(96.89)$ & $321.18(106.34)$ \\
\hline KCAL & $2385.80(726.51)$ & $2281.33(823.33)$ \\
\hline
\end{tabular}

${ }^{\dagger}$ NAFLD: Non-alcoholic fatty liver disease; ${ }^{\ddagger}$ SBP: Systolic blood pressure; $§$ DBP: Diastolic blood pressure HOMA-IR. Homeostatic model assessment of Insulin Resistance; $\mu$ GFR. Estimated glomerular filtration rate; i GOT glutamate-oxalacetate transaminase; ${ }^{¥}$ GPT glutamate-pyruvate transaminase; ! GGT gamma-glutamil transferase; ${ }^{\#}$ HDL cholesterol: High density lipoprotein cholesterol; ‘ FT3 free triiodothyronine; ${ }^{\$}$ FT4 Free thyroxine.

Table 3 shows Odds Ratio (ORs) for Foods Groups. No statistically significant association was observed.

Table 4 shows fully adjusted ORs for food groups components, classified as disease protective or promoting foods in relation to NAFLD severity, respectively. It is worthy of note that the average daily consumption (g/day) of winter ice-cream was higher in moderate than severe NAFLD. A statistically significant negative association between NAFLD severity and winter ice-cream intake, chickpeas intake, and aged cheeses (local), was evidenced. Conversely, a statistically significant positive association was observed between NAFLD severity and white bread, fats, and rabbit meat. 
Table 3. Food Groups by NAFLD Severity. NutriAtt Study. Castellana Grotte (BA), Italy.

\begin{tabular}{|c|c|c|c|}
\hline & \multicolumn{2}{|c|}{ NAFLD $^{\dagger}$} & \\
\hline & Moderate & Severe & \\
\hline Foods (g/day) & Mean (a) & Mean (a) & OR $(95 \%$ CI) (a) \\
\hline Milk And Yogurt & 450.21 & 448.79 & $0.99(0.99-1.00)$ \\
\hline Sweet Products Milk Based & 17.75 & 18.37 & $1.00(0.97-1.03)$ \\
\hline Aged Cheeses & 34.79 & 26.23 & $0.98(0.97-1.00)$ \\
\hline Cheeses & 23.59 & 22.93 & $0.99(0.98-1.02)$ \\
\hline Meets And EgGs & 117.78 & 133.60 & $1.00(0.99-1.01)$ \\
\hline Meat Products & 20.64 & 20.12 & $0.99(0.98-1.02)$ \\
\hline Non-Starchy Vegetables & 152.50 & 166.43 & $1.00(0.99-1.01)$ \\
\hline FrUITS & 383.33 & 314.78 & $0.99(0.99-1.00)$ \\
\hline DRIED FRUITS & 11.30 & 9.92 & $0.99(0.98-1.01)$ \\
\hline Refined Grains & 74.89 & 79.85 & $1.00(0.99-1.01)$ \\
\hline Whole Grains & 6.80 & 6.32 & $0.99(0.96-1.03)$ \\
\hline LEGUMES & 50.02 & 42.66 & $0.99(0.98-1.00)$ \\
\hline Starchy Vegetables & 38.82 & 46.93 & $1.01(0.99-1.02)$ \\
\hline Added Sugar And Sweets & 33.81 & 25.26 & $0.99(0.97-1.00)$ \\
\hline Paste, Bisquits And Bread Rolls & 217.23 & 216.86 & $0.99(0.99-1.00)$ \\
\hline FATS & 23.72 & 27.37 & $1.03(0.99-1.07)$ \\
\hline Alcoholic Beverages & 115.79 & 165.25 & $1.00(0.99-1.00)$ \\
\hline TeA Coffee & 125.95 & 133.41 & $1.00(0.99-1.00)$ \\
\hline Non-Alcoholic Caloric Beverages & 91.27 & 125.79 & $1.00(0.99-1.00)$ \\
\hline SOUCES DRESSINGS & 7.40 & 9.97 & $1.02(0.99-1.05)$ \\
\hline FISH & 41.14 & 42.40 & $1.00(0.99-1.02)$ \\
\hline
\end{tabular}

(a) Age, sex, and Kcal adjusted mean and ORs; ${ }^{+}$NAFLD: Non-alcoholic Liver Fatty Disease.

Table 4. Protective and promoting foods by NAFLD severity. NutriAtt Study. Castellana Grotte (BA), Italy.

\begin{tabular}{|c|c|c|c|c|}
\hline & \multicolumn{2}{|c|}{ NAFLD $^{\dagger}$} & & \\
\hline & Moderate & Severe & & \\
\hline Foods (g/day) & Mean (a) & Mean (a) & OR (95\% CI) (a) & OR $(95 \% C I)(a, b)$ \\
\hline \multicolumn{5}{|l|}{ Protective Foods } \\
\hline Chocolate & 6.99 & 4.02 & $0.95(0.90-0.99)^{* *}$ & $0.94(0.84-1.05)$ \\
\hline WiNTER ICECREAM & 2.21 & 0.88 & $0.82(0.70-0.96)^{* *}$ & $0.65(0.47-0.89)$ * \\
\hline ApricoATS & 8.35 & 4.94 & $0.95(0.90-0.99)^{* *}$ & $0.95(0.82-1.10)$ \\
\hline Pears & 56.84 & 35.09 & $0.99(0.99-0.99)^{* *}$ & $0.99(0.98-1.01)$ \\
\hline SoYa MiLK & 15.59 & 5.04 & $0.98(0.97-0.99)^{* *}$ & $0.99(0.97-1.02)$ \\
\hline Legumes-Rice & 1.60 & 0.68 & $0.83(0.69-0.98)^{* *}$ & $0.73(0.50-1.06)$ \\
\hline Chickpeas & 1.95 & 1.19 & $0.71(0.56-092) *$ & $0.57(0.34-0.97)^{* *}$ \\
\hline Dried Peas & 1.63 & 0.97 & $0.69(0.51-0.94)^{* *}$ & $0.78(0.44-1.39)$ \\
\hline Local Aged Cheeses & 34.79 & 26.23 & $0.99(0.98-1.00)$ & $0.85(0.74-0.98)^{* *}$ \\
\hline \multicolumn{5}{|l|}{ Promoting Foods } \\
\hline Industrial Aged Cheeses & 31.85 & 25.41 & $0.88(0.78-0.99)^{* *}$ & $1.17(1.01-1.35)^{* *}$ \\
\hline WhITE BREAD & 17.81 & 39.08 & $1.01(1.00-1.02)^{* *}$ & $1.02(0.99-1.04)$ \\
\hline SweEt Milk-Nowinter ICECreAm & 17.75 & 18.37 & $1.01(0.98-1.05)$ & $1.11(1.01-1.21)^{* *}$ \\
\hline FreNCH Fries & 3.23 & 6.58 & $1.06(0.99-1.12)$ & $1.10(0.99-1.24)$ \\
\hline FATS & 23.72 & 27.37 & $1.03(0.99-1.07)$ & $1.12(1.01-1.25)^{* *}$ \\
\hline Rabitt Meat & 1.71 & 3.80 & $1.12(1.01-1.24)^{* *}$ & $1.23(1.01-1.49)^{* *}$ \\
\hline
\end{tabular}

(a) Age, sex, and Kcal adjusted mean and ORs; (b) Adjusted for all food groups without protective foods and promoting foods that are present in the table. ${ }^{\dagger}$ NAFLD: Non-alcoholic fatty liver disease ${ }^{*} p<0.01 ;{ }^{* *} p<0.05$. 


\section{Discussion}

This study showed that some food groups components were associated with a lower or a higher risk of developing severe NAFLD, and that, within the same Food Group, some components with a protective or promoter action are present. In particular, winter ice-cream was associated with a 35\% lower risk of severe NAFLD per g/day intake. Conversely, the Sweet Products Milk-Based food group (without winter ice-cream) resulted associated with an $11 \%$ higher risk of severe NAFLD per g/day intake. Among the Aged Cheeses food group, only those industrially produced were associated with a $17 \%$ higher risk of severe NAFLD per g/day intake.

Moreover, in the group of protective foods, in addition to winter ice-cream, chickpeas were associated with a $43 \%$ lower risk of severe NAFLD per g/day intake. Conversely for "promoting foods" in addition to industrially produced Aged cheeses, Sweet Products Milk-Based Food Group (without winter ice-cream), the Fats group comprising: seed oil, peanut oil, butter, sunflower oil, corn oil, margarine, olive oil, extra virgin olive oil, soy oil, were associated with a $12 \%$ higher risk of severe NAFLD per g/day intake. Also, rabbit meat was associated with a $23 \%$ higher risk of severe NAFLD per g/day intake.

As regards olive oil, a component of the Mediterranean Diet well known for its healthy effects in human beings, we did not find any effect when it was isolated from the Fats Group. This finding is not surprising because a high olive oil consumption is widespread in this region and so all subjects are exposed to much the same level of intake [20].

\subsection{Effect of Food Groups Components on NAFLD}

\subsubsection{Legumes}

A higher intake of legumes, especially beans and lentils, has been associated with a lower waist circumference, serum cholesterol, and blood pressure [21] and lower prevalence of NAFLD [22]. Obesity is found in $30 \%$ to $100 \%$ of subjects with NAFLD, and steatosis is 4.6 -fold higher in obese compared to normal-weight individuals [23]. Dietary protein may reduce weight by increasing energy consumption and stimulating satiety [24]. Moreover, fiber and phytate reduce the digestibility, energy availability, and glycemic response, leading to the satiety sensation [25]. A large proportion of NAFLD patients has type 2 diabetes [26], and previous studies have shown that the intake of nutrient-dense and low energy foods is inversely related to the type 2 diabetes risk [27]. The low glycemic index of legumes can have beneficial effects on type 2 diabetes [28]. Moreover, it has been shown that the consumption of pulses improves glycemic control markers in individuals with or without type 2 diabetes [29], and could improve the lipid profile and decrease lipid peroxidation due to their high fiber content and low glycemic index [30].

In this region, pulses intake is particularly high. "La Farinella di Putignano" is a flour obtained from the grinding of roasted chickpeas and barley with added salt. This product was prepared locally as from ancient times and is commonly used across all social classes [31]. It is used as a real seasoning, ending up with pasta in sauce, soups, vegetable salads, seasoned olives, or fresh figs and fruit. This precious food is still present today on the every-day table of Apulians.

\subsubsection{Aged Cheeses}

Cheese and milk products are a rich source of so-called bioactive peptides [32]. In particular, animal studies suggest that the renin-angiotensin-aldosterone system (RAAS) could be of significant importance in the pathogenesis of NAFLD. The angiotensin-converting enzyme inhibitors (ACE-I) and angiotensin receptor blockers (ARBs) are therefore a potentially useful therapeutic approach [33]. The renin-angiotensin system (RAAS) seems to play an important role also in hepatic inflammation and fibrogenesis. Angiotensin II (ANG II) is recognized to induce hepatic inflammation and to stimulate a range of fibrogenic actions predominantly throughout the AT1 receptor [34]. Aged Cheeses such as Parmesan and Grana Padano are characterized by high nutritional quality effects and contain substances 
that have a particular biological activity, and therefore they can be fully considered functional foods, according to the European Union guidelines [35].

To date, there would appear to be no studies linking the consumption of aged cheeses and NAFLD; however, the presence of peptides with an ACE-I action has been shown in aged cheeses like Parmesan/GP, and also an effect of ACE-I on preventing fatty liver in rats has been demonstrated. [33,34].

\subsubsection{Winter Ice-Cream}

In winter, ice-cream intake is frequent, but exclusively craftsman-made not packaged. Non-industrial production of ice-cream is made with a different type of milk as the animals are fed in a different way, and so the milk has a different nutritional value.

The quantity and quality of milk produced by cows depend strongly on many factors. In this sense, the transition period is a critical moment in dairy cow-feeding in traditional systems, where cows are converted from pasture to an indoor system. The consequent changes in nutrition might affect the quantity and quality of the milk [36]. Conventional milk has a greater range of different parameter seasonal variations than organic milk. These differences are particularly evident in spring and autumn, during the indoor period, due to the different diet given in organic versus conventional farms [37].

The safety and quality of dairy products are considered to be of significant importance for human health [38]. Worldwide, about $50 \%$ of all antibiotics production is used in animal and agriculture applications [7,8]. Since the 1990s, the use of antibiotics has been regulated, and maximum residue limits (MRLs) have been set [39]. Nevertheless, residues are still reported to be present in milk, at levels exceeding the MRLs worldwide $[9,38]$. The risk of consuming milk containing antimicrobial residues, even when present below the MRL, is also of great concern in regard to human health. The long-term bioaccumulation of antibiotic residues may result in bacterial resistance [7,8], hypersensitivity reactions [7,39], gastrointestinal and liver problems [9], as well as triggering cancer, mutagenicity, and toxicity in humans [40].

\subsubsection{Rabbit Meat}

Worldwide, rabbit meat is valued for its high nutritional properties [41]. Compared to other meat types (chicken, beef, and pork), it was found that rabbit meat was richer in calcium $(21.4 \mathrm{mg} / 100 \mathrm{~g})$ and phosphorus $(347 \mathrm{mg} / 100 \mathrm{~g})$ and lower in fat $(9.2 \mathrm{~g} / 100 \mathrm{~g})$ and cholesterol $(56.4 \mathrm{mg} / 100 \mathrm{~g})$ [42]. The intensification of production systems and concurrent exposure to different stressors, antibiotics at sub-therapeutic levels, have widely affected rabbits. During the last decades, considerable amounts of antibiotics have been used in animal production. Therapeutic use of antibiotics is typically a high dose-short term regimen. Growth promoting use is typically the opposite, i.e., a low dose-long term administration, usually given in feed [43].

\subsection{Antibiotics}

It has been proposed that gut microbiota may be involved in the pathogenesis of obesity, possibly through effects on energy balance, nutrient absorption, inflammatory pathways, and the gut-brain axis [44,45]. Human and animal studies have established a strong association between a perturbed microbiome and the development of obesity and related metabolic dysfunctions [45]. These studies showed that antibiotic exposure substantially altered the gut microbiota and that adding a high calorie, high-fat diet increased the effects of the altered microbiota on both adiposity and hepatic gene expression [46]. As the acquisition of the intestinal microbiota begins at birth, the disruption of the microbiota during maturation by low-dose antibiotic exposure can alter host metabolism and adiposity [46,47]. However, data linking gut dysbiosis with the severity of NAFLD remain poorly documented in humans. Only a few series with generally small sample sizes, heterogeneous populations (adult versus children), and different methods for gut microbiota evaluation (qPCR versus pyrosequencing) are available in the literature [48]. 
Some methodological issues need to be considered. As this is a RCT with strict inclusion criteria, the sample size calculation was performed to obtain precise estimates, and the outcome assessment method has high sensitivity and specificity. Transient elastography with controlled attenuation parameter has demonstrated good accuracy in quantifying not only the levels of liver steatosis but also fibrosis in NAFLD. The method is fast, reliable and reproducible and has good intra- and interobserver levels of agreement. This characteristic gives it good properties to be used in population studies. Moreover, some initial technical difficulties to screen obese subjects have been overcome with the development of specific probes [49].

Reverse causation could matter in this type of patients. Reverse causation or temporal bias, ordinarily refers to the situation in which the outcome precedes and causes the exposure instead of the other way around [50]. It is unlikely that our subjects had changed their eating habits because in the majority of cases they were not aware of NAFLD. The subjects did not seek medical attention and came to participate as a way of improving their lifestyle, as indicated by the generalist.

Moreover, several confounding factors were considered to ensure that the estimates could be not only precise but also accurate. Limitations include the use of FFQ, although the instrument is highly standardized. In this case, exposure misclassification matters. However, if an exposure misclassification bias were introduced in the design, as the proportion of exposed/non-exposed subjects does not depend on the outcome, any bias introduced by nondifferential misclassification of the exposure is predictably only in one direction, namely, toward the null hypothesis [51].

\section{Conclusions}

In conclusion, there were consistent associations, either after adjustment, among some food group components and severity of NAFLD. These interesting associations need to be verified with longitudinal studies as it could help to elaborate personalized dietary counseling to treat NAFLD. It also emerged that the way food is produced, and the way animals are bred, would seem to play a role in rendering these foods promoters of the risk of worsening NAFLD.

Author Contributions: A.R.O. and A.M. equally contributed to the conception and design of the research. C.B. (Caterina Bonfiglio) and P.S. contributed to the formal analysis.; A.M., I.F., C.M.L., R.C., M.N., V.D.N., V.G. and V.T., equally contributed to the investigation; I.B., C.B. (Claudia Buongiorno), A.C., V.D., A.P., F.P. and P.S. contributed to the acquisition of data; A.M. drafted the manuscript; A.R.O. contributed to writing reviewing and editing manuscript; A.R.O. supervision.; A.R.O. project administration.

Funding: This work was funded by a grant from the Italian Ministry of Health RC2015.

Conflicts of Interest: The authors declare no conflict of interest.

\section{References}

1. EASL (European Association for the Study of the Liver)-EASD (European Association for the Study of Diabetes)-EASO (European Association for the Study of Obesity) Clinical Practice Guidelines for the management of non-alcoholic fatty liver disease. J. Hepatol. 2016, 64, 1388-1402. [CrossRef] [PubMed]

2. Cozzolongo, R.; Osella, A.R.; Elba, S.; Petruzzi, J.; Buongiorno, G.; Giannuzzi, V.; Leone, G.; Bonfiglio, C.; Lanzilotta, E.; Manghisi, O.G.; et al. Epidemiology of HCV infection in the general population: A survey in a southern Italian town. Am. J. Gastroenterol. 2009, 104, 2740-2746. [CrossRef] [PubMed]

3. Veronese, N.; Notarnicola, M.; Cisternino, A.M.; Reddavide, R.; Inguaggiato, R.; Guerra, V.; Rotolo, O.; Zinzi, I.; Leandro, G.; Correale, M.; et al. Coffee Intake and Liver Steatosis: A Population Study in a Mediterranean Area. Nutrients 2018, 10, 89. [CrossRef] [PubMed]

4. Ghaemi, A.; Taleban, F.A.; Hekmatdoost, A.; Rafiei, A.; Hosseini, V.; Amiri, Z.; Homayounfar, R.; Fakheri, H. How Much Weight Loss is Effective on Nonalcoholic Fatty Liver Disease? Hepat. Mon. 2013, 13, e15227. [CrossRef] [PubMed] 
5. Misciagna, G.; Del Pilar Diaz, M.; Caramia, D.V.; Bonfiglio, C.; Franco, I.; Noviello, M.R.; Chiloiro, M.; Abbrescia, D.I.; Mirizzi, A.; Tanzi, M.; et al. Effect of a Low Glycemic Index Mediterranean Diet on Non-Alcoholic Fatty Liver Disease. A Randomized Controlled Clinici Trial. J. Nutr. Health Aging 2017, 21, 404-412. [CrossRef] [PubMed]

6. Rahimlou, M.; Yari, Z.; Hekmatdoost, A.; Alavian, S.M.; Keshavarz, S.A. Ginger Supplementation in Nonalcoholic Fatty Liver Disease: A Randomized, Double-Blind, Placebo-Controlled Pilot Study. Hepat. Mon. 2016, 16, e34897. [CrossRef] [PubMed]

7. Ruegg, P. Antimicrobial Residues and Resistance: Understanding and Managing Drug Usage on Dairy Farms. Available online: https:/pdfs.semanticscholar.org/35d1/c3052246743a44d97fecd59248272a9d2de2.pdf (accessed on 6 September 2019).

8. Rama, A.; Lucatello, L.; Benetti, C.; Galina, G.; Bajraktari, D. Assessment of antibacterial drug residues in milk for consumption in Kosovo. J. Food Drug Anal. 2017, 25, 525-532. [CrossRef] [PubMed]

9. Aalipour, F.; Mirlohi, M.; Jalali, M. Prevalence of antibiotic residues in commercial milk and its variation by season and thermal processing methods. Int. J. Environ. Health Eng. 2013, 2, 41.

10. Notarnicola, M.; Caruso, M.G.; Tutino, V.; Bonfiglio, C.; Cozzolongo, R.; Giannuzzi, V.; De Nunzio, V.; De Leonardis, G.; Abbrescia, D.I.; Franco, I.; et al. Significant decrease of saturation index in erythrocytes membrane from subjects with non-alcoholic fatty liver disease (NAFLD). Lipids Health Dis. 2017, 16, 160. [CrossRef] [PubMed]

11. Chiloiro, M.; Caruso, M.G.; Cisternino, A.M.; Inguaggiato, R.; Reddavide, R.; Bonfiglio, C.; Guerra, V.; Notarnicola, M.; De Michele, G.; Correale, M.; et al. Ultrasound evaluation and correlates of fatty liver disease: A population study in a Mediterranean area. Metab. Syndr. Relat. Disord. 2013, 11, 349-358. [CrossRef] [PubMed]

12. Berzigotti, A. Getting closer to a point-of-care diagnostic assessment in patients with chronic liver disease: Controlled attenuation parameter for steatosis. J. Hepatol. 2014, 60, 910-912. [CrossRef] [PubMed]

13. Sasso, M.; Tengher-Barna, I.; Ziol, M.; Miette, V.; Fournier, C.; Sandrin, L.; Poupon, R.; Cardoso, A.C.; Marcellin, P.; Douvin, C.; et al. Novel controlled attenuation parameter for noninvasive assessment of steatosis using Fibroscan (R): Validation in chronic hepatitis C. J. Viral. Hepat. 2012, 19, 244-253. [CrossRef] [PubMed]

14. Skinner, H.A.; Sheu, W.J. Reliability of alcohol use indices. The Lifetime Drinking History and the MAST. J. Stud. Alcohol. 1982, 43, 1157-1170. [CrossRef] [PubMed]

15. International Physical Activity Questionnaire. Available online: https://sites.google.com/site/theipaq/ (accessed on 6 September 2019).

16. ACC/AHA/AAPA/ABC/ACPM/AGS/APhA/ASH/ASPC/NMA/PCNA Guideline for the Prevention, Detection, Evaluation, and Management of High Blood Pressure in Adults: Executive Summary: A Report of the American College of Cardiology/American Heart Association Task Force on Clinical Practice Guidelines. Hypertension 2018, 72, e33. [CrossRef]

17. Riboli, E.; Hunt, K.J.; Slimani, N.; Ferrari, P.; Norat, T.; Fahey, M.; Charrondiere, U.R.; Hemon, B.; Casagrande, C.; Vignat, J.; et al. European Prospective Investigation into Cancer and Nutrition (EPIC): Study populations and data collection. Public Health Nutr. 2002, 5, 1113-1124. [CrossRef] [PubMed]

18. Mikolasevic, I.; Orlic, L.; Franjic, N.; Hauser, G.; Stimac, D.; Milic, S. Transient elastography (FibroScan (R)) with controlled attenuation parameter in the assessment of liver steatosis and fibrosis in patients with nonalcoholic fatty liver disease-Where do we stand? World J. Gastroenterol. 2016, 22, 7236-7251. [CrossRef] [PubMed]

19. World Health Organization. Obesity: Preventing and Managing the Global Epidemic; Report of a WHO consultation; World Health Organization: Geneva, Switzerland, 2000.

20. Piroddi, M.; Albini, A.; Fabiani, R.; Giovannelli, L.; Luceri, C.; Natella, F.; Rosignoli, P.; Rossi, T.; Taticchi, A.; Servili, M.; et al. Nutrigenomics of extra-virgin olive oil: A review. Biofactors 2017, 43, 17-41. [CrossRef] [PubMed]

21. Pappalardo, G.; Lusk, J.L. The role of beliefs in purchasing process of functional foods. Food Qual. Prefer. 2016, 53, 151-158. [CrossRef]

22. Bahrami, A.; Teymoori, F.; Eslamparast, T.; Sohrab, G.; Hejazi, E.; Poustchi, H.; Hekmatdoost, A. Legume intake and risk of nonalcoholic fatty liver disease. Indian J. Gastroenterol. 2019, 38, 55-60. [CrossRef] [PubMed]

23. Angulo, P. Nonalcoholic fatty liver disease. N. Engl. J. Med. 2002, 346, 1221-1231. [CrossRef] [PubMed] 
24. Lejeune, M.P.; Westerterp, K.R.; Adam, T.C.; Luscombe-Marsh, N.D.; Westerterp-Plantenga, M.S. Ghrelin and glucagon-like peptide 1 concentrations, 24-h satiety, and energy and substrate metabolism during a high-protein diet and measured in a respiration chamber. Am. J. Clin. Nutr. 2006, 83, 89-94. [CrossRef] [PubMed]

25. Anderson, G.H.; Woodend, D. Effect of glycemic carbohydrates on short-term satiety and food intake. Nutr. Rev. 2003, 61, S17-S26. [CrossRef] [PubMed]

26. Paschos, P.; Paletas, K. Non alcoholic fatty liver disease and metabolic syndrome. Hippokratia 2009, 13, 9-19. [PubMed]

27. Rebello, C.J.; Greenway, F.L.; Finley, J.W. A review of the nutritional value of legumes and their effects on obesity and its related co-morbidities. Obes. Rev. Off. J. Int. Assoc. Study Obes. 2014, 15, 392-407. [CrossRef] [PubMed]

28. Villegas, R.; Gao, Y.T.; Yang, G.; Li, H.L.; Elasy, T.A.; Zheng, W.; Shu, X.O. Legume and soy food intake and the incidence of type 2 diabetes in the Shanghai Women's Health Study. Am. J. Clin. Nutr. 2008, 87, 162-167. [CrossRef] [PubMed]

29. Sievenpiper, J.L.; Kendall, C.W.; Esfahani, A.; Wong, J.M.; Carleton, A.J.; Jiang, H.Y.; Bazinet, R.P.; Vidgen, E.; Jenkins, D.J. Effect of non-oil-seed pulses on glycaemic control: A systematic review and meta-analysis of randomised controlled experimental trials in people with and without diabetes. Diabetologia 2009, 52, 1479-1495. [CrossRef] [PubMed]

30. Zhang, Z.; Lanza, E.; Kris-Etherton, P.M.; Colburn, N.H.; Bagshaw, D.; Rovine, M.J.; Ulbrecht, J.S.; Bobe, G.; Chapkin, R.S.; Hartman, T.J. A high legume low glycemic index diet improves serum lipid profiles in men. Lipids 2010, 45, 765-775. [CrossRef] [PubMed]

31. Esposito, G. I Tumulti di Putignano del 1902 e la morte di Margherita Pusterla, Atti Parlamentari, Sentenze, Pubblicistica e Carte Comunali; Edizioni Regione Puglia ed.: Via de Curtis, Mottola, 2004.

32. Moller, N.P.; Scholz-Ahrens, K.E.; Roos, N.; Schrezenmeir, J. Bioactive peptides and proteins from foods: Indication for health effects. Eur. J. Nutr. 2008, 47, 171-182. [CrossRef] [PubMed]

33. Paschos, P.; Tziomalos, K. Nonalcoholic fatty liver disease and the renin-angiotensin system: Implications for treatment. World J. Hepatol. 2012, 4, 327-331. [CrossRef] [PubMed]

34. Toblli, J.E.; Munoz, M.C.; Cao, G.; Mella, J.; Pereyra, L.; Mastai, R. ACE inhibition and AT1 receptor blockade prevent fatty liver and fibrosis in obese Zucker rats. Obesity 2008, 16, 770-776. [CrossRef] [PubMed]

35. Summer, A.; Formaggioni, P.; Franceschi, P.; Di Frangia, F.; Righi, F.; Malacarne, M. Cheese as Functional Food: The Example of Parmigiano Reggiano and Grana Padano. Food Technol. Biotechnol. 2017, 55, 277-289. [CrossRef] [PubMed]

36. Kuczynska, B.; Puppel, K.; Golebiewski, M.; Metera, E.; Sakowski, T.; Sloniewski, K. Differences in whey protein content between cow's milk collected in late pasture and early indoor feeding season from conventional and organic farms in Poland. J. Sci. Food Agric. 2012, 92, 2899-2904. [CrossRef] [PubMed]

37. Petrov, P.; Zhukova, Y.; Yuriy, D. The effects of Dairy Management on Milk Quality Characteristics. Turk. J. Agric. Food Sci. Technol. 2016, 4, 782-786. [CrossRef]

38. Al Zuheir, I.M. Detection of $\beta$-lactams and tetracyclines antimicrobial residues in raw dairy milk for human consumption in Palestine. Walailak J. Sci. Tech. 2012, 9, 277-279.

39. Adesokan, H.K.; Agada, C.A.; Adetunji, V.O.; Akanbi, I.M. Oxytetracycline and penicillin-G residues in cattle slaughtered in south-western Nigeria: Implications for livestock disease management and public health. J. S. Afr. Vet. Assoc. 2013, 84, 945-950. [CrossRef] [PubMed]

40. Moghadam, M.M.; Amiri, M.; Riabi, H.R.; Riabi, H.R. Evaluation of Antibiotic Residues in Pasteurized and Raw Milk Distributed in the South of Khorasan-e Razavi Province, Iran. J. Clin. Diagn. Res. 2016, 10, Fc31-Fc35. [CrossRef] [PubMed]

41. Dalle Zotte, A.; Szendro, Z. The role of rabbit meat as functional food. Meat Sci. 2011, 88, 319-331. [CrossRef] [PubMed]

42. Nistor, E.; Bampidis, V.A.; Păcală, N.; Pentea, M.; Tozer, J.; Prundeanu, H. Nutrient content of rabbit meat as compared to chicken, beef and pork meat. Nutrient content of rabbit meat as compared to chicken, beef and pork meat. J. Anim. Prod. Adv. 2013, 3, 172-176. [CrossRef] 
43. Falcão-e-Cunha, L.; Castro Solla, L.; Maertens, L.; Marounek, M.; Pinheiro, V.; Freire, J.; Mourão, J.L. Alternatives to antibiotic growth promoters in rabbit feeding: A review. World Rabbit Sci. 2007, 15, 127-140.

44. Cox, L.M.; Blaser, M.J. Pathways in microbe-induced obesity. Cell Metab. 2013, 17, 883-894. [CrossRef] [PubMed]

45. Le Roy, T.; Llopis, M.; Lepage, P.; Bruneau, A.; Rabot, S.; Bevilacqua, C.; Martin, P.; Philippe, C.; Walker, F.; Bado, A.; et al. Intestinal microbiota determines development of non-alcoholic fatty liver disease in mice. Gut 2013, 62, 1787-1794. [CrossRef] [PubMed]

46. Cox, L.M.; Yamanishi, S.; Sohn, J.; Alekseyenko, A.V.; Leung, J.M.; Cho, I.; Kim, S.G.; Li, H.; Gao, Z.; Mahana, D.; et al. Altering the intestinal microbiota during a critical developmental window has lasting metabolic consequences. Cell 2014, 158, 705-721. [CrossRef] [PubMed]

47. Mahana, D.; Trent, C.M.; Kurtz, Z.D.; Bokulich, N.A.; Battaglia, T.; Chung, J.; Müller, C.L.; Li, H.; Bonneau, R.A.; Blaser, M.J. Antibiotic perturbation of the murine gut microbiome enhances the adiposity, insulin resistance, and liver disease associated with high-fat diet. Genome Med. 2016, 8, 48. [CrossRef] [PubMed]

48. Mouzaki, M.; Comelli, E.M.; Arendt, B.M.; Bonengel, J.; Fung, S.K.; Fischer, S.E.; McGilvray, I.D.; Allard, J.P. Intestinal microbiota in patients with nonalcoholic fatty liver disease. Hepatology 2013, 58, 120-127. [CrossRef] [PubMed]

49. Szklo, M.; Nieto, F.J. Epidemiology Beyond the Basics, 4th ed.; Bartlett, J.A., Ed.; Jones \& Bartlett Publishers: Burlington, MA, USA, 2014.

50. Rothman, K.J.; Greenland, S.; Lash, T.L. Modern Epidemiology, 3rd ed.; Wolters Kluwer Health/Lippincott Williams \& Wilkins: Philadelphia Wilkins, PA, USA, 2008.

51. Copeland, K.T.; Checkoway, H.; McMichael, A.J.; Holbrook, R.H. Bias due to misclassification in the estimation of relative risk. Am. J. Epidemiol. 1977, 105, 488-495. [CrossRef] [PubMed]

(C) 2019 by the authors. Licensee MDPI, Basel, Switzerland. This article is an open access article distributed under the terms and conditions of the Creative Commons Attribution (CC BY) license (http://creativecommons.org/licenses/by/4.0/). 